Article

\title{
The Internal Relation between Quantum Chemical Descriptors and Empirical Constants of Polychlorinated Compounds
}

\author{
Jiangchi Fei ${ }^{1}$, Qiming Mao ${ }^{2}$, Lu Peng ${ }^{3}$, Tiantian Ye ${ }^{4}$, Yuan Yang ${ }^{2, *}$ and Shuang Luo ${ }^{2, *}$ \\ 1 Institute of Environmental Engineering, School of Metallurgy and Environment, Central South University, \\ Changsha 410083, China; jack-fei@csu.edu.cn \\ 2 College of Resources and Environment, Hunan Agricultural University, Changsha 410128, China; \\ qimingmao@126.com \\ 3 College of Biology and Environmental Sciences, Jishou University, Jishou 416000, China; \\ abonluo@gmail.com \\ 4 South China Institute of Environmental Sciences, Ministry of Environmental Protection, Guangzhou 510655, \\ China; yetiantian@scies.org \\ * Correspondence: yangyuan@hunau.edu.cn (Y.Y.); luoshuang@csu.edu.cn or shuangluo@hunau.edu.cn (S.L.); \\ Tel.: +86-151-1120-6841 (S.L.)
}

Academic Editor: Kok Hwa Lim

Received: 11 October 2018; Accepted: 6 November 2018; Published: 10 November 2018

\begin{abstract}
Quantum chemical descriptors and empirical parameters are two different types of chemical parameters that play the fundamental roles in chemical reactivity and model development. However, previous studies have lacked detail regarding the relationship between quantum chemical descriptors and empirical constants. We selected polychlorinated biphenyls (PCBs) as an object to investigate the intrinsic correlation between 16 quantum chemical descriptors and Hammett constants. The results exhibited extremely high linearity for $\sum \sigma_{\mathrm{o}, \mathrm{m}, \mathrm{p}}^{+}$with $\mathrm{Q}_{\mathrm{xx} / \mathrm{yy} / \mathrm{zz}}, \alpha$ and $E_{\mathrm{HOMO}}$ based on the meta-position grouping. Polychlorinated dibenzodioxins (PCDDs) and polychlorinated naphthalenes (PCNs) congeners, as two independent compounds, validated the reliability of the relationship. The meta-substituent grouping method between $\sum \sigma_{\mathrm{O}, \mathrm{m}}^{+} \mathrm{p}$ and $\alpha$ was successfully used to predict the rate constant $(k)$ for ${ }^{\bullet} \mathrm{OH}$ oxidation of PCBs, as well as the octanol/water partition coefficient $\left(\log K_{\mathrm{OW}}\right)$ and aqueous solubility $\left(-\log S_{W}\right)$ of PCDDs, and exhibited excellent agreement with experimental measurements. Revealing the intrinsic correlation underlying the empirical constant and quantum chemical descriptors can develop simpler and higher efficient model application in predicting the environmental behavior and chemical properties of compounds.
\end{abstract}

Keywords: quantum chemical descriptor; Hammett constant; meta-position; prediction model

\section{Introduction}

Computational chemistry is defined as a mathematical description of chemistry that is an effective tool to investigate the kinetics and rate constant of chemical reactions, develop a predictive model, and calculate the properties of molecules to obtain some quantum chemical descriptors [1]. Quantum chemical descriptors play a fundamental role in chemistry, environmental protection, pharmaceutical science, and health research [2], as they identify the correlations between chemical structures and properties (i.e., quantitative structure-activity relationship, QSAR) [3-6]. A large number of geometrical, electrostatic, and quantum information regarding molecules can be presented by computational chemistry software. Thus, many descriptors reflect the properties of molecules and can provide insight into the chemical nature of compounds under given reaction conditions [7-9]. For example, the descriptors $E_{\mathrm{LUMO}}$ (energy of lowest unoccupied molecular orbital) and $E_{\mathrm{HOMO}}$ 
(highest occupied molecular orbital) reflect the molecular orbital energies $[1,10,11]$, which play an important role in predominating many chemical reactions and determining molecular electronic transition [1,12]. The $E_{\mathrm{HOMO}}$ and $E_{\mathrm{LUMO}}$ are directly related to the ionization potential and electron affinity, and characterize the susceptibility of molecules toward attack by electrophiles and nucleophiles, respectively [1]. Another descriptor polarizability is dependent on the electron distribution of the entire molecule, which determines the dynamical response to external fields, and provides insight into a molecular internal structure $[13,14]$.

Molecular descriptors derived from quantum chemical calculations have been widely used for the prediction and interpretation of quantitative aspects of organic reactions [1,15-18]. For example, Luo et al. [19] investigated the UV direct photolysis of ibuprofen and sulfamethoxazole based on experimental measurements, and further accounted for its mechanism based on $E_{\mathrm{LUMO}}-E_{\mathrm{HOMO}}$ descriptor. The small $E_{\mathrm{LUMO}}-E_{\mathrm{HOMO}}$ gap values presented the lower excitation energy and higher quantum yield, which accounted for the high photolysis rate value [19]. Xiao et al. developed a QSAR model to predict the second-order rate constants for $\mathrm{SO}_{4}^{\bullet-}$ degradation of emerging micro-pollutants $\left(k_{\mathrm{SO}_{4}^{-}}\right)$based on the ratio of oxygen to carbon atoms (\#O:C) and the $E_{\mathrm{LUMO}}-E_{\mathrm{HOMO}}: \ln k_{\mathrm{SO}_{4}^{\circ-}}=26.8-3.97 \times(\# \mathrm{O}: \mathrm{C})-0.75 \times\left(E_{\mathrm{LUMO}}-E_{\mathrm{HOMO}}\right)$. The model provided a robust predictive tool for estimating emerging micropollutants removal by $\mathrm{SO}_{4}{ }^{\bullet-}$ mediated process [20]. More importantly, the QSAR model combining quantum chemical descriptors and experimental data can predict unobserved chemical phenomena in some cases. Although quantum chemical descriptors can provide a more accurate and detailed description of electronic effects than empirical methods, quantum chemical descriptors calculated at a higher level of theory are still difficult to obtain [21,22]. Thereby, chemical descriptor calculation is an expensive and difficult process, which limits the high-efficiency prediction at the screening level [21-23]. Furthermore, another type of empirical parameter is determined by experimentations under the same experimental constraints and controls, and a common understanding of measurement. An empirical parameter is a similar effect on the properties or reactivity of each compound in a series of structurally related compounds [24], such as acid dissociation constant $(p \mathrm{Ka})$, octanol/water partition coefficient $\left(\log k_{\mathrm{OW}}\right)$, and substituent constants. As an important empirical constant, the Hammett substituent constants $(\sigma)$ has provided insight into the relationship between reactivity and chemical structures containing aromatic rings [25]. Although this type of constant is reckoned to be accurate, simple, and have a low computational cost, it still neglects the isomers and the steric effects that exert a great influence on chemical activity $[23,26]$. Instead, the QSAR model reflects the structural and chemical reactivity of the molecule and exhibits advantages for an empirical constant model [14,20,27]. For instance, Russell et al. [28] revealed that Henry's law constant could be approximated as a linear function of factors related to bulk, lipophilicity, and polarity based on 63 molecular structures. Overall, both the QSAR model and empirical constants reflect the relationship regarding structure-activity of compounds [29]; there may be a connection between the quantum chemical descriptor and empirical constant. The intrinsic relationship underlying the quantum chemical descriptor and empirical constant still needs to be revealed.

Thus, how to combine the advantage of quantum chemical descriptors and empirical constants to develop an efficient, accurate, and simple model is quite meaningful to study. However, there rarely have been other reports about the relationship between quantum chemical descriptors and empirical constants are rare. Santiago et al. [25] developed a mathematical modeling approach to incorporate steric effects in Hammett-type correlations. They found a strong correlation between the Hammett values of para-substitution and natural bond orbital $(\mathrm{NBO})$ charges $\left(R^{2}=0.96\right)$. The Hammett values can be used as an alternative to NBO charges [25]. Our previous study had tried to trap the relationship among polychlorinated compounds between polarizability ( $\alpha$, a quantum chemical descriptor) and Hammett constant ( $\sigma$, an empirical constant) [21], which based on two good models $\left(\log k=-11.6-1.39 \times \sum \sigma_{\mathrm{o}, \mathrm{m}, \mathrm{p}}^{+}[30]\right)$ and $\alpha(\ln k=-0.054 \times \alpha-19.49$ [14] $)$ to predicted the kinetics of $\bullet \mathrm{OH}$ oxidation of PCBs ( $k$ values) in gas-phase. However, the findings were haphazard and limited. 
Revealing the relationships hidden in quantum chemical descriptors and empirical constants will greatly improve the efficiency and accuracy of the prediction model. More importantly, the revelation relationship will disclose the intrinsic correlation between structure and apparent experiment. In this study, we selected a class of polychlorinated compounds, polychlorinated biphenyls (PCBs) as an object because of 210 compounds with similar structures and multiple substitution positions, in order to investigate the relationships between 16 quantum chemical descriptors and Hammett constants. Another two classes of polychlorinated compounds, polychlorinated dibenzodioxins (PCDDs) and polychlorinated naphthalenes (PCNs) congeners, were selected to validate the obtained relationship. To reveal the intrinsic correlation underlying empirical constants and quantum chemical descriptors can provide a simpler and higher efficient method with great application potential for model development. The result will help develop fast and tractable prediction power in predicting the phenomenon of polychlorinated compounds involving environmental pollution and chemical properties.

\section{Results and Discussion}

\subsection{Reveal Relationships between Quantum Descriptors and Hammett Constants}

The Hammett constant (including $\sigma, \sigma^{+}$and $\sigma^{-}$) is a reflection of the electronic nature and position of the substituent [31]. There have been multiple positions substituted by $\mathrm{Cl}$ atoms at the ortho-, meta-, and para-positions, respectively (Figure S1). Thus, the $\sum \sigma_{\mathrm{o}, \mathrm{m}, \mathrm{p}}, \sum \sigma_{\mathrm{o}, \mathrm{m}, \mathrm{p}}^{+}$, and $\sum \sigma_{\mathrm{o}, \mathrm{m}, \mathrm{p}}^{-}$values are the sum of all of the substituent constants of the $\mathrm{Cl}$ atoms attached to the aromatic ring, respectively corresponding to $\sigma_{\mathrm{o}, \mathrm{m}, \mathrm{p}}, \sigma_{\mathrm{o}, \mathrm{m}, \mathrm{p}}^{+}$and $\sigma_{\mathrm{o}, \mathrm{m}, \mathrm{p}}^{-}$values (the $\mathrm{o}, \mathrm{m}$, and $\mathrm{p}$ represent the substitution on the ortho-, meta- and para-positions, respectively) (in Table S1) [6,31]. Sixteen quantum chemical descriptors (Table S2) were obtained from the optimized results.

For 210 PCBs congeners, the relationships among 16 quantum chemical descriptors with $\sum \sigma_{\mathrm{o}, \mathrm{m}, \mathrm{p}}, \sum \sigma_{\mathrm{o}, \mathrm{m}, \mathrm{p}}^{+}$, and $\sum \sigma_{\mathrm{o}, \mathrm{m}, \mathrm{p}}^{-}$values were listed in Figure S2, Figure 1 and Figure S3, respectively. The different values of $\sum \sigma_{\mathrm{o}}, \mathrm{m}, \mathrm{p}, \sum \sigma_{\mathrm{o}}^{+} \mathrm{m}, \mathrm{p}$, and $\sum \sigma_{\mathrm{o}, \mathrm{m}, \mathrm{p}}^{-}$values were 72,74 and 44, respectively. In other words, many different structures of PCBs congeners were faced with the same sigma values. The results showed that there have been significantly different trends among $\sum \sigma_{\mathrm{o}, \mathrm{m}, \mathrm{p}}, \sum \sigma_{\mathrm{o}, \mathrm{m}, \mathrm{p}}^{+}$, and $\sum \sigma_{\mathrm{o}, \mathrm{m}, \mathrm{p}}^{-}$for the same quantum chemical descriptors. There are five obvious five groups of linear correlation pattern of $\sum \sigma_{\mathrm{o}, \mathrm{m}, \mathrm{p}}^{+}$and $Q_{\mathrm{xx} / \mathrm{yy} / \mathrm{zz}}, \alpha$, and $E_{\mathrm{HOMO}}$, respectively. However, the single linear trend for $\sum \sigma_{\mathrm{o}, \mathrm{m}, \mathrm{p}}$ and the vertical trend were shown for $\sum \sigma_{\mathrm{o}}^{-} \mathrm{m}, \mathrm{p}$, respectively. All of relationship for others descriptors with $\sum \sigma_{\mathrm{o}, \mathrm{m}, \mathrm{p}}, \sum \sigma_{\mathrm{o}, \mathrm{m}, \mathrm{p}}^{+}$and $\sum \sigma_{\mathrm{o}, \mathrm{m}, \mathrm{p}}^{-}$values were scatter distribution, except for $\eta$ and $S$ converging toward a baseline. It's worth noting that only a single linear for 210 congers did not distinguish more information relative to the five obvious linear correlation groups. It is worth mentioning that $\sigma_{\mathrm{o}}^{-}=\sigma_{\mathrm{p}}^{-}$ and $\sigma_{\mathrm{m}}^{-}=2 \sigma_{\mathrm{p}}^{-}=2 \sigma_{\mathrm{o}}^{-}$, which caused the points of $\sum \sigma_{\mathrm{o}, \mathrm{m}, \mathrm{p}}^{-}$and descriptors concentrated distribution into 15 approximations and hid more discrepant information. Thus, the high relationships among $Q_{\mathrm{xx} / \mathrm{yy} / \mathrm{zz}}, \alpha, E_{\mathrm{HOMO}}$ and $\sum \sigma_{\mathrm{o}, \mathrm{m}, \mathrm{p}}^{+}$were selected for further analysis in this study, respectively. 

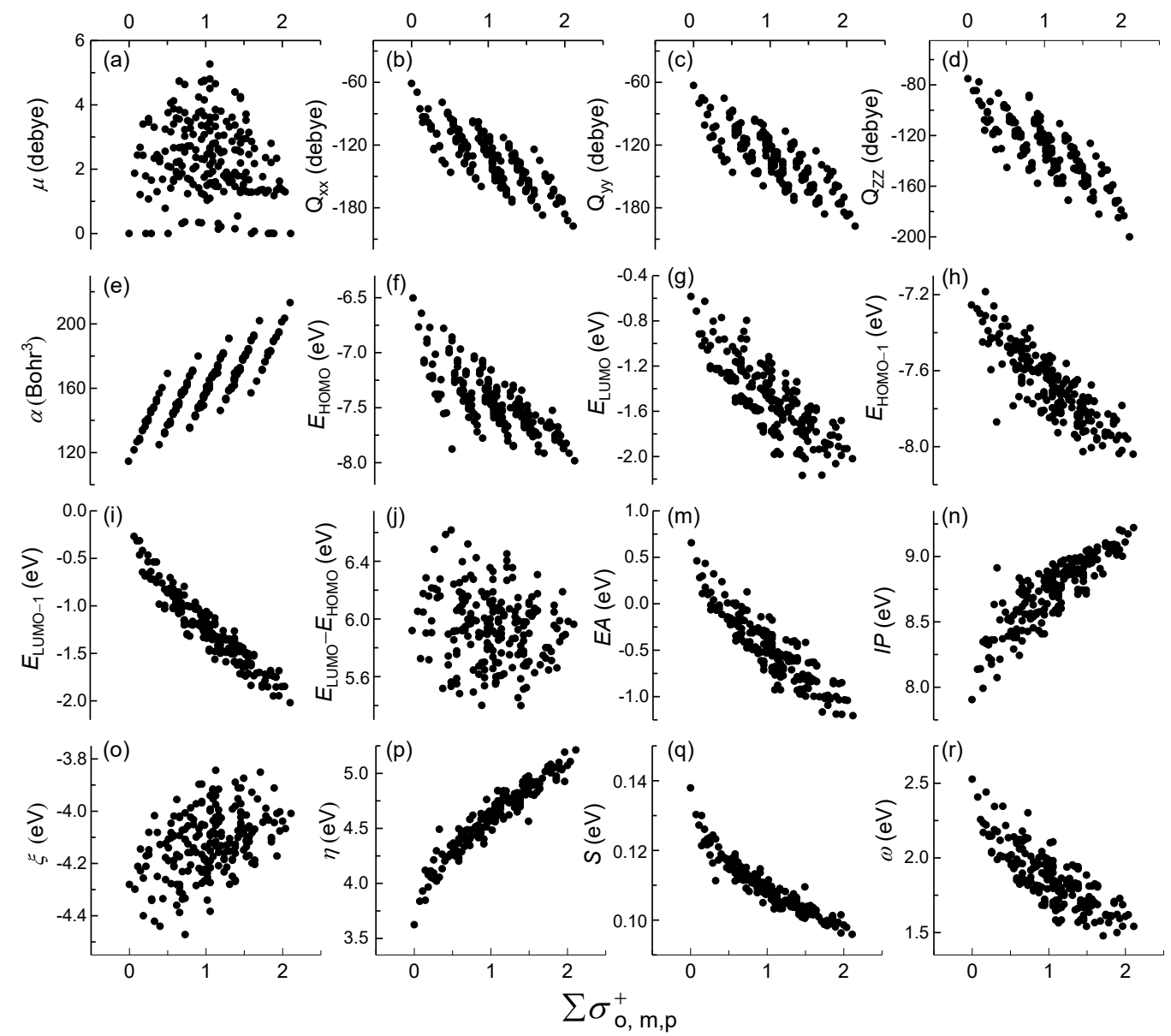

Figure 1. Relationships of 16 quantum chemical descriptors (a-r) and $\sum \sigma_{0, m}^{+}, \mathrm{p}$ for polychlorinated biphenyls (PCBs) congeners. The (a), (b) referred to our previous study [21].

\subsection{Mechanistic Interpretation of Internal Relationship}

The further investigation result showed that $Q_{\mathrm{xx} / \mathrm{yy} / \mathrm{zz}}, \alpha$, and $E_{\mathrm{HOMO}}$ all displayed extremely high linearly correlation to $\sum \sigma_{\mathrm{o}, \mathrm{m}, \mathrm{p}}^{+}$(Figure 2 and Figure S4). The result showed that all of the PCBs congeners are classified into five clusters according to the number of $\mathrm{Cl}$ atoms substituted at the meta-position ( $\left.\mathrm{N}_{\mathrm{m}-\mathrm{Cl}}\right)$ on the ring. As shown in Figure 2, there are 21, 48, 72, 48, and 21 congeners in each group for meta-position with $\mathrm{N}_{\mathrm{m}-\mathrm{Cl}}$ ranging from 0 to 4 , respectively. In each meta-position cluster, $Q_{\mathrm{xx} / \mathrm{yy} / \mathrm{zz}}$ and $E_{\mathrm{HOMO}}$ values decrease with the increase of $\sum \sigma_{\mathrm{o}, \mathrm{m}, \mathrm{p}}^{+}$while $\alpha$ values increase with the increase of $\sum \sigma_{\mathrm{o}, \mathrm{m}, \mathrm{p}}^{+}$. The $R^{2}$ for $Q_{\mathrm{xx} / \mathrm{yy} / \mathrm{zz}}$, and $\alpha$ with $\sum \sigma_{\mathrm{o}, \mathrm{m}, \mathrm{p}}^{+}$were $0.836 \sim 0.935$ and $0.987 \sim 0.994$, respectively, which were higher the $R^{2}$ for $E_{\mathrm{HOMO}}$ with $\sum \sigma_{\mathrm{o}, \mathrm{m}, \mathrm{p}}(0.759 \sim 0.824)$. The extremely high $R^{2}(>0.7)$ indicated that the meta-position chlorination on PCBs congeners play a crucial role in the relationship between $\sum \sigma_{\mathrm{o}, \mathrm{m}, \mathrm{p}}^{+}$and $Q_{\mathrm{xx} / \mathrm{yy} / \mathrm{zz}}$ and $\alpha$ and $E_{\mathrm{HOMO}}$. Furthermore, the trend for $Q_{\mathrm{xx} / \mathrm{yy} / \mathrm{zz}}$ $\alpha$, and $E_{\mathrm{HOMO}}$ values also supported that meta-position determined the reactivity of PCBs. The highly linear correlation illustrated that the simple $\sum \sigma_{\mathrm{o}, \mathrm{m}, \mathrm{p}}^{+}$can be used to explain or substitute complex quantum chemical descriptors, such as $Q_{\mathrm{xx} / \mathrm{yy} / \mathrm{zz}}, \alpha$, and $E_{\mathrm{HOMO}}$, based on meta-substitute grouping. Their corresponding fitted linear equations were listed in Table $1\left(\sum \sigma_{\mathrm{o}, \mathrm{m}, \mathrm{p}}^{+}\right.$and $\left.Q_{\mathrm{xx}}, \alpha, E_{\mathrm{HOMO}}\right)$ and Table S3 $\left(\sum \sigma_{\mathrm{o}, \mathrm{m}, \mathrm{p}}^{+}\right.$and $\left.Q_{\mathrm{yy}}, Q_{\mathrm{zz}}\right)$. 


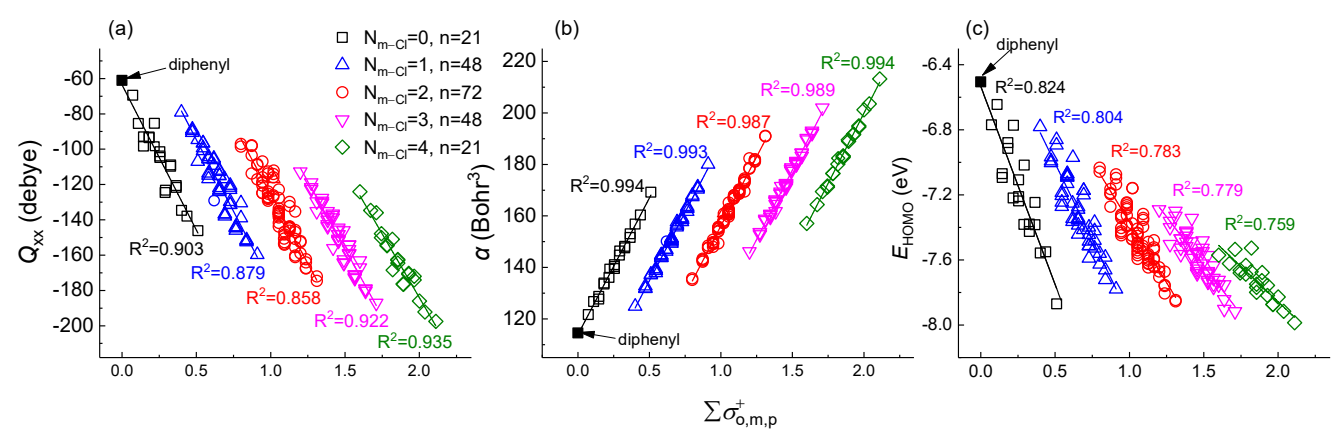

Figure 2. The relationship of $\sum \sigma_{\mathrm{o}, \mathrm{m}, \mathrm{p}}^{+}$and quadrupole moment tensor along the $\mathrm{x}$ axis $\left(Q_{\mathrm{xx}}\right)$, polarizability $(\alpha)$ [21] and energy of the highest occupied molecular orbital ( $\left.E_{\mathrm{HOMO}}\right)$ for PCBs congeners. The $\mathrm{N}_{\mathrm{m}-\mathrm{Cl}}$ represents the number of $\mathrm{Cl}$ atoms substituted at the meta-position, ranging from 0 to 4 with the number of congeners $\mathrm{n}=21,48,72,48$, and 21, respectively. (a) $\sum \sigma_{\mathrm{o}, \mathrm{m}, \mathrm{p}}^{+}$and $Q_{\mathrm{xx}} ;$ (b) $\sum \sigma_{\mathrm{o}, \mathrm{m}, \mathrm{p}}^{+}$and $\alpha ;(\mathbf{c}) \sum \sigma_{\mathrm{o}, \mathrm{m}, \mathrm{p}}^{+}$and $E_{\mathrm{HOMO}}$

Table 1. The fitted linear equations of $\sum \sigma_{\mathrm{o}, \mathrm{m}, \mathrm{p}}^{+}$with $Q_{\mathrm{xx}}, \alpha$ and $E_{\mathrm{HOMO}}$ for PCBs congeners.

\begin{tabular}{ccccc|ccc|ccc}
\hline \multirow{2}{*}{$\#$} & \multirow{2}{*}{$\sum \sigma_{\mathbf{o}, \mathbf{m}, \mathbf{p}}^{+}$Range } & \multicolumn{2}{c|}{$Q_{\mathbf{x x}}=\mathbf{A} \times \sum \sigma_{\mathbf{0}, \mathbf{m}, \mathbf{p}}^{\mathbf{+}} \mathbf{B}$} & \multicolumn{2}{c}{$\alpha=\mathbf{A} \times \sum \sigma_{\mathbf{0}, \mathbf{m}, \mathbf{p}}^{+} \mathbf{B}[21]$} & \multicolumn{3}{c}{$\boldsymbol{E}_{\text {HOMO }}=\mathbf{A} \times \sum \sigma_{\mathbf{0}, \mathbf{m}, \mathbf{p}^{+} \mathbf{B}}$} \\
\cline { 3 - 12 } & & $\mathbf{A}$ & $\mathbf{B}$ & $\boldsymbol{R}^{\mathbf{2}}$ & $\mathbf{A}$ & $\mathbf{B}$ & $\boldsymbol{R}^{\mathbf{2}}$ & $\mathbf{A}$ & $\mathbf{B}$ & $\boldsymbol{R}^{\mathbf{2}}$ \\
\hline $\mathrm{N}_{\mathrm{m}-\mathrm{Cl}}=0$ & $0 \sim 0.51$ & -164.46 & -63.53 & 0.903 & 106.13 & 113.94 & 0.994 & -2.44 & -6.53 & 0.824 \\
$\mathrm{~N}_{\mathrm{m}-\mathrm{Cl}}=1$ & $0.4 \sim 0.91$ & -162.23 & -13.51 & 0.879 & 106.38 & 81.72 & 0.993 & -1.88 & -6.06 & 0.804 \\
$\mathrm{~N}_{\mathrm{m}-\mathrm{Cl}}=2$ & $0.8 \sim 1.31$ & -156.71 & 31.14 & 0.858 & 107.73 & 48.49 & 0.987 & -1.49 & -5.88 & 0.783 \\
$\mathrm{~N}_{\mathrm{m}-\mathrm{Cl}}=3$ & $1.2 \sim 1.71$ & -152.50 & 72.28 & 0.922 & 107.67 & 16.33 & 0.989 & -1.20 & -5.84 & 0.779 \\
$\mathrm{~N}_{\mathrm{m}-\mathrm{Cl}}=4$ & $1.6 \sim 2.11$ & -144.53 & 104.95 & 0.935 & 108.87 & -17.84 & 0.994 & -0.87 & -6.12 & 0.759 \\
\hline
\end{tabular}

In order to gain insights into their connections, the intrinsic characters of $Q_{\mathrm{xx} / \mathrm{yy} / \mathrm{zz}}, \alpha$ and $E_{\mathrm{HOMO}}$ need further to be further revealed. The $\sum \sigma_{\mathrm{o}, \mathrm{m}, \mathrm{p}}^{+}$is an empirical value reflecting the electronic nature and position of the substituent [31]. The quadrupole moment $\left(Q_{\mathrm{xx}}, Q_{\mathrm{yy}}, Q_{\mathrm{zz}}\right)$ reflects the distribution of the molecular charge in the $\mathrm{x}_{-}, \mathrm{y}-$, and $\mathrm{z}$-coordinates or the departure degree relative to the spherical-symmetry [32]. The polarizability $(\alpha)$ is defined as the ratio of the induced dipole moment of a molecule to the electric field that produces its dipole moment [33], which is an important electronic descriptor to reflect the electron distribution in the molecule [34] that is well correlated to the overall reactivity of molecule $[13,35,36]$. $E_{\mathrm{HOMO}}$ characterizes the susceptibility of a molecule toward attack by electrophiles. A molecule with higher $E_{\mathrm{HOMO}}$ is more reactive to attack by strong electrophiles [14,21]. Some investigations have shown that $Q_{\mathrm{xx} / \mathrm{yy} / \mathrm{zz}}, \alpha$ and $E_{\mathrm{HOMO}}$ are associated with many chemical activities and properties. For instance, Kim and Mhin et al. suggested that the change in the polarity of the quadrupole moment $\left(Q_{\mathrm{xx} / \mathrm{yy} / \mathrm{zz}}\right)$ was related to the reduction of the repulsive interaction, which played a vital role in governing the geometry of aromatics $[37,38]$. The investigation reported by Zeng et al. indicated that the quadrupole moment $\left(Q_{y y}\right.$ and $\left.Q_{z z}\right)$ were successfully used to develop a model for predicting the $n$-octanol/water partition coefficients $\left(\log K_{\mathrm{OW}}\right)$ and aqueous solubility coefficients $\left(-\log S_{W}\right)$ of PCDDs $[39,40]$. In addition, our previous study developed a QSAR model to predict the ${ }^{\bullet} \mathrm{OH}$ degradation of PCBs based on single descriptor $\alpha$. The $\alpha$ played an important role in determining the reaction rate $(k)$ [14]. Luo et al. suggested that the more polarizable $(\alpha)$ the molecule, the easier an approaching electrophile (or nucleophile) can distort the electron density of the aromatic molecule increasing the rate of reaction [21]. For $E_{\mathrm{HOMO}}$ descriptor, Yan et al. developed a QSAR model for ${ }^{\bullet} \mathrm{OH}$ oxidation of the multiring hydrocarbon in the gas-phase based on partial least squares regression [41]. They reported that $E_{\mathrm{HOMO}}$ was the most suitable for model development and the higher $E_{\mathrm{HOMO}}$ value corresponds to higher reactivity. Thus, $\sum \sigma_{\mathrm{O}, \mathrm{m}, \mathrm{p}}^{+}$can be considered as the intuitive experimental phenomenon of the structure descriptor, as $\mathrm{Q}_{\mathrm{xx} / \mathrm{yy} / \mathrm{zz}}, \alpha$ and $E_{\mathrm{HOMO}}$, and so on.

Due to $\mathrm{Q}_{\mathrm{xx} / \mathrm{yy} / \mathrm{zz},} \alpha$, and $E_{\mathrm{HOMO}}$ having highly correlated to $\sum \sigma_{\mathrm{o}}^{+} \mathrm{m}, \mathrm{p}$, there may be collinearity between $Q_{\mathrm{xx} / \mathrm{yy} / \mathrm{zz}}, \alpha$, and $E_{\mathrm{HOMO}}$. Further, Figure 3 showed that $\alpha$ with $Q_{\mathrm{xx}}$ and $E_{\mathrm{HOMO}}$ had a high correlation, with corresponding $R^{2}$ values of 0.94 and 0.81 , respectively. Meanwhile, $\alpha$ and 
$Q_{\mathrm{yy}} / Q_{\mathrm{zz}}$ had similarly high correlation (in Figure $\mathrm{S} 5$, the $R^{2}$ values were 0.92 and 0.95 , respectively). The quadrupole moment $\left(Q_{\mathrm{xx}}, Q_{\mathrm{yy}}, Q_{\mathrm{zz}}\right)$ and $\alpha$ reflect the electron behavior and the homogeneity in the electronic properties of the molecule. The $\alpha$, as one of the molecular electrostatic descriptors [14,20], is the principal factor determining the structure-activity relationship, even though $E_{\mathrm{HOMO}}$ represents the electron-donating power of the molecule [42]. Yang et al. suggested that the $E_{\mathrm{HOMO}}$ reflected only a single aspect of the molecule, while the $\alpha$ incorporated a number of molecular features [14].

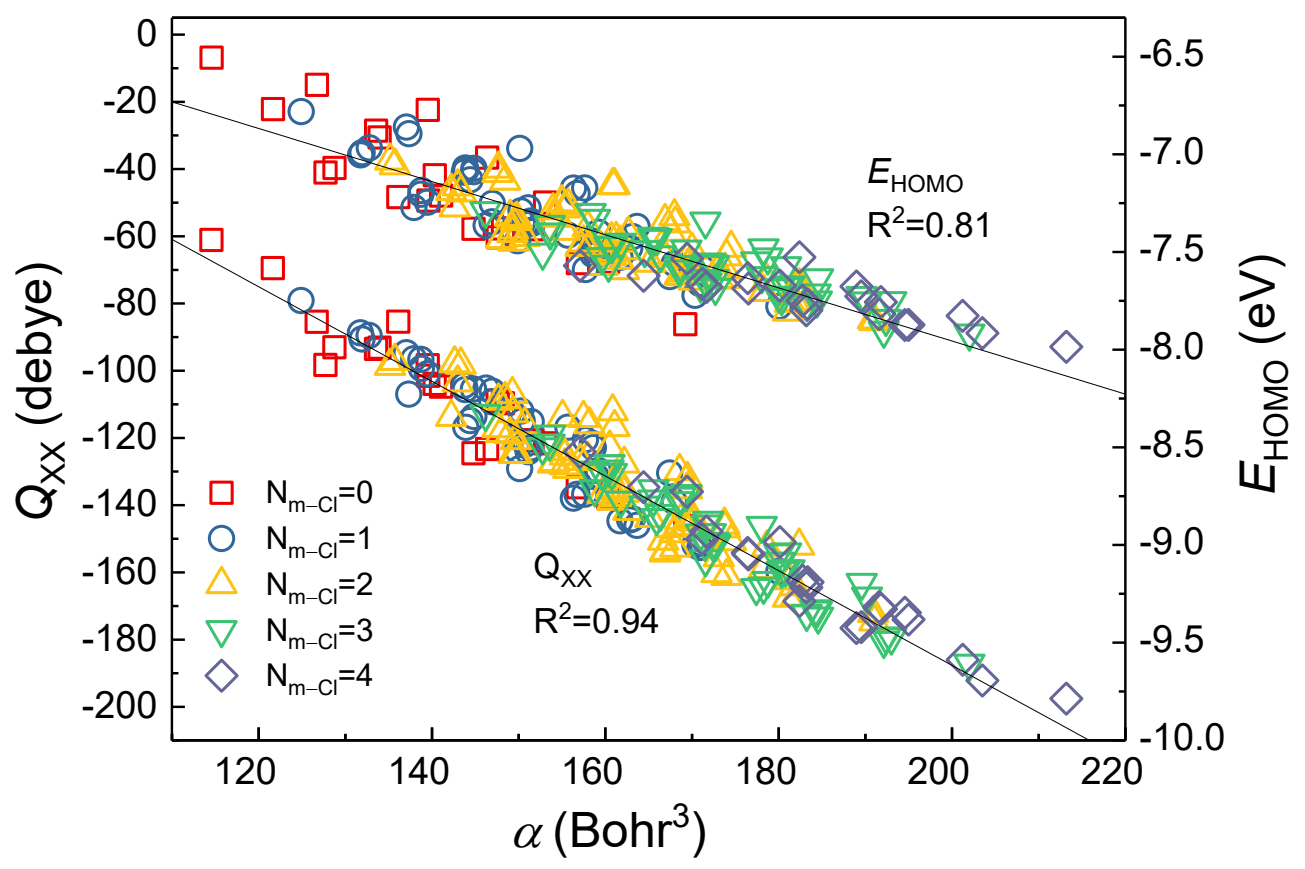

Figure 3. The relationship of $\alpha$ with $\mathrm{Q}_{\mathrm{xx}}$ and $E_{\mathrm{HOMO}}$ of PCBs congeners.

The reasons for good performance with aromatic meta-substituent grouping regarding the relationships of quantum chemical descriptors and $\sum \sigma_{\mathrm{o}, \mathrm{m}, \mathrm{p}}^{+}$need to be further discussed. First of all, the $\sigma_{\mathrm{m}}^{+}$value $(0.4)$ over $\sigma_{\mathrm{p}}^{+}(0.11)$ and $\sigma_{\mathrm{o}}^{+}(0.073)$ for $\mathrm{Cl}$ substituents was probably attributed to the meta-position, which determined its dominant role and showed the high correlation [21]. Another important reason, since $\mathrm{Cl}$ atoms are substituted on aromatic rings, is electron withdrawing through the $\sigma$-bond, which decreases the ring electron density in the $\mathrm{Cl}$ atoms' substituted site $[9,14]$. The $\mathrm{Cl}$ atoms that were substituted at the meta-position can pull electrons from the aromatic ring, resulting in decreased electron density and suppressed HOMO distribution [14,21]. The HOMO distribution is the most direct reflection of the changes in electron distribution. Figure S6 listed the $\mathrm{HOMO}$ distribution of $\mathrm{Cl}$ atoms with different $\mathrm{N}_{\mathrm{m}-\mathrm{Cl}}$ numbers at meta-position and $\mathrm{N}_{\mathrm{o}-\mathrm{Cl}}$ at ortho-position. Luo et al. investigated the changed of HOMO distribution and $\mathrm{Cl}$ atoms at the meta-position [21]. The HOMO distribution of $\mathrm{Cl}$ atoms at the meta-position increased independent of the increasing number of $\mathrm{Cl}$ atoms at the meta-position. However, with the increasing number of $\mathrm{Cl}$ atoms at the meta-position, the HOMO distribution of the 1-, 2-, 6-, $1^{\prime}-, 2^{\prime}-, 6^{\prime}$-positions in the biphenyl ring (PCB15, PCB28, PCB100, and PCB155) was easily distorted and greatly varied. For the $\mathrm{Cl}$ atoms increasing at the meta-position and ortho-position, the $\mathrm{Cl}$ atoms at the meta-position (PCB15, PCB37, PCB81, PCB126, and PCB169) do not change the HOMO distribution in the biphenyl junction. However, once $\mathrm{Cl}$ atoms are added at the ortho-position (PCB66, PCB123, PCB167, and PCB189), their HOMO distribution of biphenyl junction and meta-position were greatly influenced and obviously changed. It is helpful to deepen our understanding of why meta-position played an important role in correlating $\alpha$ to $\sum \sigma_{\mathrm{o}, \mathrm{m}, \mathrm{p}}^{+}$in high linearity. However, the HOMO distribution is easily distorted and greatly varied when $\mathrm{Cl}$ atoms are substituted in other positions [21]. 


\subsection{Application of Meta-Substituent Grouping}

\subsubsection{Application in Similar Compounds}

The aromatic meta-substituent grouping method was suitable for the application of PCBs congeners; however, a good method should also be applied to other similar compounds. Thus, in order to confirm the aromatic meta-substituent grouping method, we examined the relationships of $\sum \sigma_{\mathrm{o}, \mathrm{m}, \mathrm{p}}$ and quantum chemical descriptors $\left(\mathrm{Q}_{\mathrm{xx} / \mathrm{yy} / \mathrm{zz}}, \alpha\right.$ and $\left.E_{\mathrm{HOMO}}\right)$ with $\mathrm{Cl}$ atoms substituted at meta-position for PCDDs and PCNs congeners (Figures S7 and S8). For PCDDs and PCNs with only 25 different $\sum \sigma_{\mathrm{o}, \mathrm{m}, \mathrm{p}}^{+}$values, the trends in the relationships of $\sum \sigma_{\mathrm{o}, \mathrm{m}, \mathrm{p}}^{+}$and $\mathrm{Q}_{\mathrm{xx} / \mathrm{yy} / \mathrm{zz}}$ $\alpha$, and $E_{\mathrm{HOMO}}$ were similar to those of the PCBs based on aromatic meta-substituent grouping. For PCDD, these parallel lines exhibited extremely high linearity for $\sum \sigma_{\mathrm{o}}^{+} \mathrm{m}, \mathrm{p}$ with $\alpha\left(R^{2}=0.994 \sim 0.999\right)$ and $E_{\mathrm{HOMO}}\left(R^{2}=0.982 \sim 0.999\right)$; however, the linearity for $\sum \sigma_{\mathrm{o}, \mathrm{m}, \mathrm{p}}^{+}$and $\mathrm{Q}_{\mathrm{xx} / \mathrm{yy} / \mathrm{zz}}$ were acceptable $\left(R^{2}=0.712 \sim 0.999\right)$ (Table S8). For PCNs, the parallel lines $\mathrm{Q}_{\mathrm{xx} / \mathrm{yy} / \mathrm{zz}}$ and $\alpha$ also exhibited extremely high linearity $\left(R^{2}=0.883 \sim 0.999\right)$ except for $E_{\mathrm{HOMO}}$, while the linearity of $E_{\mathrm{HOMO}}$ was not obvious $\left(R^{2}=0.438 \sim 0.677\right)$ (Table S9). The reason may be that the HOMO distribution is severely disturbed by the naphthalene ring structure relative to the biphenyl structure for PCBs and the dibenzodioxin structure for PCDDs, especially for the alpha positions in the naphthalene ring. The overall trends of $\mathrm{Q}_{\mathrm{xx} / \mathrm{yy} / \mathrm{zz},} \alpha$ and $E_{\mathrm{HOMO}}$ with $\sum \sigma_{\mathrm{o}, \mathrm{m}, \mathrm{p}}$ are correlated to the number of $\mathrm{Cl}$ atoms substituted on the meta-position as well. The validation results of PCNs and PCDDs support the application domain in aromatic compounds based on the meta-substituent grouping method.

\subsubsection{Application in Prediction Model}

Our previous study was the first to predict the $k$ values of ${ }^{\bullet} \mathrm{OH}$ degradation of PCBs in the gas-phase based on the QSAR model and $\alpha$ [21]. The observed lnk values of ${ }^{\bullet} \mathrm{OH}$ oxidation of PCBs congeners (as validation data) were listed in Table S6. The result showed that the prediction $k$ values were excellently consistent with experimental measurements (the validation coefficient $Q^{2}=0.825$, the standard deviation $\Delta \operatorname{lnk}=-0.430 \sim 0.626$, and the average of standard deviation $\overline{\Delta \operatorname{lnk}}=-0.03$ ), and exhibited greater predictive power and convenience than the QSAR model for single $\alpha$ descriptor (Table 2). We also developed the meta-substituent grouping model to predict the $\log K_{\mathrm{OW}}$ and $-\log S_{\mathrm{W}}$ of PCDDs based on the existent quantum chemical descriptor model $\left(\log K_{\mathrm{OW}}=0.03345 \times \alpha+0.39092\right.$ and $-\log S_{\mathrm{W}}=0.0693 \times \alpha-3.6425$ ) (Table 2) and observed values (Table S7) in this study [43-45]. The results showed that the standard deviation $\Delta \log K_{\mathrm{OW}}$ and $\Delta-\log S_{\mathrm{W}}$ ranged from -0.15 to 0.92 and from -0.25 to -1.45 , and the average of standard deviation $\overline{\Delta \log K_{\mathrm{OW}}}$ and $\overline{\Delta-\log S_{\mathrm{W}}}$ were 0.45 and -0.92 , respectively. The $Q^{2}$ between the prediction and observation values were 0.954 and 0.981 , respectively. All of the models showed that the $p<0.01$. These statistical diagnostics demonstrated that the predicted values of $\log K_{\mathrm{OW}}$ and $-\log S_{\mathrm{W}}$ were very accurate, which indicated that the method of combining the empirical Hammett constant and quantum-chemical descriptor based on meta-substituent grouping showed fast and tractable prediction power and a great application potential for model development.

Table 2. The model based on $\sum \sigma_{\mathrm{o}, \mathrm{m}, \mathrm{p}}^{+}$and meta-substituent grouping for predicting ${ }^{\bullet} \mathrm{OH}$ oxidation of PCBs, $\log K_{\mathrm{OW}}$ and $-\log S_{\mathrm{W}}$ of polychlorinated dibenzodioxins (PCDDs).

\begin{tabular}{cccc}
\hline \multicolumn{2}{c}{ Congeners } & Model & Statistical Diagnostic \\
\hline \multirow{4}{*}{ PCBs } & $\mathrm{N}_{\mathrm{m}-\mathrm{Cl}}=0$ & $\ln k=-5.73 \times \sum \sigma_{\mathrm{O}, \mathrm{m}, \mathrm{p}}^{+}-25.64$ & $\overline{\Delta \operatorname{lnk}}=-0.03$ \\
& $\mathrm{~N}_{\mathrm{m}-\mathrm{Cl}}=1$ & $\ln k=-5.74 \times \sum \sigma_{\mathrm{O}, \mathrm{m}, \mathrm{p}}^{+}-23.90$ & $Q^{2}=0.825$ \\
& $\mathrm{~N}_{\mathrm{m}-\mathrm{Cl}}=2$ & $\ln k=-5.82 \times \sum \sigma_{\mathrm{O}, \mathrm{m}, \mathrm{p}}^{+}-22.11$ & $\mathrm{~F}=113$ \\
& $\mathrm{~N}_{\mathrm{m}-\mathrm{Cl}}=3$ & $\ln k=-5.81 \times \sum \sigma_{\mathrm{O}, \mathrm{m}, \mathrm{p}}^{+}-20.37$ & $p<0.01$ \\
& $\mathrm{~N}_{\mathrm{m}-\mathrm{Cl}}=4$ & $\ln k=-5.88 \times \sum \sigma_{\mathrm{o}, \mathrm{m}, \mathrm{p}}^{+}-18.53$ & {$[21]$} \\
\hline
\end{tabular}


Table 2. Cont.

\begin{tabular}{|c|c|c|c|}
\hline \multicolumn{2}{|c|}{ Congeners } & Model & Statistical Diagnostic \\
\hline \multirow{5}{*}{ PCDDs } & $\mathrm{N}_{\mathrm{m}-\mathrm{Cl}}=0$ & $\log K_{\mathrm{OW}}=4.60 \times \sum \sigma_{\mathrm{o}, \mathrm{m}, \mathrm{p}}^{+}+4.46$ & $\overline{\Delta \log K_{\mathrm{OW}}}=0.45$ \\
\hline & $\mathrm{N}_{\mathrm{m}-\mathrm{Cl}}=1$ & $\log K_{\mathrm{OW}}=4.70 \times \sum \sigma_{\mathrm{o}, \mathrm{m}, \mathrm{p}}^{+}+2.97$ & $Q^{2}=0.954$ \\
\hline & $\mathrm{N}_{\mathrm{m}-\mathrm{Cl}}=2$ & $\log K_{\mathrm{OW}}=4.70 \times \sum \sigma_{\mathrm{o}, \mathrm{m}, \mathrm{p}}^{+}+1.48$ & $\mathrm{~F}=314$ \\
\hline & $\mathrm{N}_{\mathrm{m}-\mathrm{Cl}}=3$ & $\log K_{\mathrm{OW}}=4.69 \times \sum \sigma_{\mathrm{o}, \mathrm{m}, \mathrm{p}}^{+}+0.02$ & $p<0.01$ \\
\hline & $\mathrm{N}_{\mathrm{m}-\mathrm{Cl}}=4$ & $\log K_{\mathrm{OW}}=4.69 \times \sum \sigma_{\mathrm{o}, \mathrm{m}, \mathrm{p}}-1.45$ & {$[43]^{*}$} \\
\hline \multirow{5}{*}{ PCDDs } & $\mathrm{N}_{\mathrm{m}-\mathrm{Cl}}=0$ & $-\log S_{\mathrm{W}}=9.52 \times \sum \sigma_{\mathrm{o}, \mathrm{m}, \mathrm{p}}^{+}+4.78$ & $\overline{\Delta-\log S_{W}}=-0.92$ \\
\hline & $\mathrm{N}_{\mathrm{m}-\mathrm{Cl}}=1$ & $-\log S_{\mathrm{W}}=9.73 \times \sum \sigma_{\mathrm{o}, \mathrm{m}, \mathrm{p}}^{+}+1.69$ & $Q^{2}=0.981$ \\
\hline & $\mathrm{N}_{\mathrm{m}-\mathrm{Cl}}=2$ & $-\log S_{\mathrm{W}}=9.74 \times \sum \sigma_{\mathrm{o}, \mathrm{m}, \mathrm{p}}^{+}-1.38$ & $F=659$ \\
\hline & $\mathrm{N}_{\mathrm{m}-\mathrm{Cl}}=3$ & $-\log S_{\mathrm{W}}=9.72 \times \sum \sigma_{\mathrm{o}, \mathrm{m}, \mathrm{p}}^{+}-4.42$ & $p<0.01$ \\
\hline & $\mathrm{N}_{\mathrm{m}-\mathrm{Cl}}=4$ & $-\log S_{\mathrm{W}}=9.72 \times \sum \sigma_{\mathrm{o}, \mathrm{m}, \mathrm{p}}^{+}-7.46$ & {$[45]^{*}$} \\
\hline
\end{tabular}

* The quantum-chemical descriptor model obtained from $\log K_{\mathrm{OW}}=0.03345 \times \alpha+0.39092$ and $-\log S_{\mathrm{W}}=0.0693 \times \alpha$ $-3.6425[43,45]$.

\section{Methods}

\subsection{Data Collection}

The experimental $k$ values of ${ }^{\bullet} \mathrm{OH}$ oxidation of PCBs (294-300 K) in gas-phase were obtained from previous study [21]. The experimental $\log K_{\mathrm{OW}}$ and $-\log S_{\mathrm{W}}$ values were collected from the studies of Huang [44] and Kim [45] et al. studies. For PCBs, PCDDs, and PCNs, these comprise in total 210, 76, and 76 congeners from non to fully (decachloro) $\mathrm{Cl}$ substituted on the benzene or naphthalene ring, respectively. Although diphenyl, dibenzo-1,4-dioxin and naphthalene did not have the substituted $\mathrm{Cl}$ atoms, they were still investigated in this study due to the structural similarities to PCBs, PCDDs and PCNs, respectively. The $\mathrm{Cl}$ substituted PCBs are classified by para (4-, $4^{\prime}-$ position), meta (3-, 5-, $3^{\prime}-, 5^{\prime}$ - position), and ortho (2-, 6-, 2'-, 6'- position) substitution patterns, and the PCDDs and PCNs are classified by meta (2-, 3-, 7-, 8- position), and ortho (1-, 4-, 6-, 9- position) substitution patterns (without para-position) (Figure S1). The Hammett constant $\sum \sigma_{\mathrm{o}, \mathrm{m}, \mathrm{p}}, \sum \sigma_{\mathrm{o}, \mathrm{m}, \mathrm{p}}^{+}$and $\sum \sigma_{\mathrm{o}, \mathrm{m}, \mathrm{p}}^{-}$values are the sum of the substituent constants $\sigma_{\mathrm{o}}+\sigma_{\mathrm{m}}+\sigma_{\mathrm{p}}, \sigma_{\mathrm{o}}^{+}+\sigma_{\mathrm{m}}^{+}+\sigma_{\mathrm{p}}^{+}$, and $\sigma_{\mathrm{o}}^{-}+\sigma_{\mathrm{m}}^{-}+\sigma_{\mathrm{p}}^{-}$respectively, which are the $\mathrm{Cl}$ atoms substituted to the aromatic ring on the ortho-, meta-, and para-positions, respectively [6,31]. The $\sigma^{+}$and $\sigma^{-}$constants represent the compounds with delocalized positive and negative charges, respectively based upon the heterolysis reaction of para-substituted cumyl chlorides and phenols [6,46]. The Hammett constants $\left(\sigma, \sigma^{-}, \sigma^{+}\right)$were described in the Supplementary Materials (Text S1) and their values are listed in Table S1 in detail.

\subsection{Quantum Chemical Descriptors Calculation}

The structures of 210 PCB congeners, 76 PCDDs, and 76 PCNs congeners (Tables S3-S5) were created by GaussView 5.0 [47]. First, the global minimum energy was optimized at Spartan'10 program [48] using the MMFF (Merck Molecular Force Field) method [49,50]. Then, the geometries were performed to further optimize in the gas-phase using Gaussian 09 (Revision C.01) [51] at the mPW1PW91 (modified Perdew-Wang exchange and Perdew-Wang 91) hybrid density functional [52,53] combination with the MIDIX+ basis set [54,55]. It is reported that the MIDIX+ basis set had a good performance-to-cost ratio for the geometrical, orbital energy and electrostatic calculations in aromatic compounds $[14,21,56]$. All of the optimization structures were the local minima on potential energy surfaces with positive vibration frequencies. Sixteen quantum chemical descriptors, including the molecular dipole moment $(\mu)$, energy of the highest occupied molecular orbital $\left(E_{\mathrm{HOMO}}\right)$, and energy of the lowest unoccupied molecular orbital $\left(E_{\mathrm{LUMO}}\right)$, energy of the second $\mathrm{HOMO}$ and LUMO $\left(E_{\mathrm{HOMO}-1}\right.$ and $\left.E_{\mathrm{LUMO}+1}\right)$, gap of $E_{\mathrm{LUMO}}$ and $E_{\mathrm{HOMO}}\left(E_{\mathrm{LUMO}}-E_{\mathrm{HOMO}}\right)$, polarizability $(\alpha)$, electron affinity $(E A)$, ionization potential $(I P)$, quadrupole moment tensor along the $\mathrm{x} / \mathrm{y} / \mathrm{z}$ axis $\left(Q_{\mathrm{xx}} / Q_{\mathrm{yy}} / Q_{\mathrm{zz}}\right)$, softness $(S)$, electronegativity $(\zeta)$, hardness $(\eta)$, and electrophilicity index 
$(\omega)$ were obtained from the optimized results. The descriptors and their formulas were introduced in detail in Table S2.

\subsection{Model Development}

The multilinear regression (MLR) analysis [57] was used to develop the meta-substituent grouping models in this study. We selected the compounds with experimental measurements $\left(26 \ln k, 17 \log K_{\mathrm{OW}}\right.$ and $15 \log S_{\mathrm{W}}$ values) to validate the predictive power based on the meta-substituent relationship (Tables S6 and S7). The standard deviation and average of the standard deviation of prediction values represent the error between the experimental and predicted values. The determination coefficient $R^{2}$ measures the observation value repeatability of the model, and the validation coefficient $Q^{2}$ reflects the correlation between predicted values and observed values. The $Q^{2}$ was calculated as following:

$$
Q^{2}=\frac{\sum_{i=1}^{n}\left(\hat{y}_{i}-\bar{y}_{i}\right)^{2}}{\sum_{i=1}^{n}\left(y_{i}-\bar{y}_{i}\right)^{2}}
$$

where $y_{i}$ and $\hat{y}_{i}$ are the observed and predicted values, respectively, and $\bar{y}$ was the average values of the predicted values. High $R^{2}$ and $Q^{2}$ values indicate a model with robust performance and good predictive power, respectively. In addition, the $R^{2}$ and $Q^{2}>0.7$ indicates the method with a better predictive performance. The statistical analyses were conducted using SPSS software version 17.0 [58].

\section{Conclusions}

In this study, we selected the PCBs as an object to investigate the relationships of 16 quantum chemical descriptors and Hammett constants in order to reveal their intrinsic correlation. By systematically analyzing the relationship of 16 quantum chemical descriptors and the Hammett relationship $\left(\sum \sigma_{\mathrm{o}, \mathrm{m}, \mathrm{p}}^{+}, \sum \sigma_{\mathrm{o}, \mathrm{m}, \mathrm{p}}\right.$ and $\left.\sum \sigma_{\mathrm{o}, \mathrm{m}, \mathrm{p}}^{-}\right)$for PCBs congeners, a very good correlation of $\sum \sigma_{\mathrm{o}, \mathrm{m}, \mathrm{p}}$ with $\mathrm{Q}_{\mathrm{xx} / \mathrm{yy} / \mathrm{zz}}, \alpha$, and $E_{\mathrm{HOMO}}$ based on meta-position grouping were observed. PCDDs and PCNs as two independent compounds validated the reliability of the relationship in aromatic compounds based on the meta-substituent grouping. Furthermore, the meta-substituent grouping method between $\sum \sigma_{\mathrm{o}, \mathrm{m}, \mathrm{p}}^{+}$and quantum chemical descriptors was successfully used for apply in predicting $\ln k$ values for ${ }^{\bullet} \mathrm{OH}$ oxidation of PCBs, as well as the $\log K_{\mathrm{OW}}$ and $-\log S_{\mathrm{W}}$ of PCDDs, which exhibit excellent agreement with experimental measurements. The results indicated that combining empirical constants and quantum chemical descriptors based on meta-substituent grouping has greater tool application for predicting the environmental behavior and chemical properties of compounds.

Supplementary Materials: The following are available online.

Author Contributions: Data curation, J.F.; Formal analysis, Q.M.; Funding acquisition, S.L.; Investigation, Q.M.; Methodology, Y.Y.; Project administration, L.P.; Validation, T.Y.; Writing—original draft, J.F. and S.L.; Writing-review \& editing, S.L.

Funding: National Nature Science Foundation of China (No. 21806035) and National key research and development plan (2016YFC0403000) is gratefully acknowledged.

Conflicts of Interest: The authors declare no conflict of interest.

\section{References}

1. Karelson, M.; Lobanov, V.S.; Katritzky, A.R. Quantum-chemical descriptors in QSAR/QSPR studies. Chem. Rev. 1996, 96, 1027-1044. [CrossRef] [PubMed]

2. Carbó, R. Molecular Similarity and Reactivity: From Quantum Chemical to Phenomenological Approaches; Springer Science \& Business Media: Berlin, Germany, 1995; Volume 14.

3. Primas, H. Chemistry, Quantum Mechanics and Reductionism: Perspectives in Theoretical Chemistry; Springer Science \& Business Media: Berlin, Germany, 2013; Volume 24. 
4. Luo, S.; Wei, Z.; Spinney, R.; Villamena, F.A.; Dionysiou, D.D.; Chen, D.; Tang, C.-J.; Chai, L.; Xiao, R. Quantitative structure-activity relationships for reactivities of sulfate and hydroxyl radicals with aromatic contaminants through single-electron transfer pathway. J. Hazard. Mater. 2018, 344, 1165-1173. [CrossRef] [PubMed]

5. Cronin, M.T.; Walker, J.D.; Jaworska, J.S.; Comber, M.H.; Watts, C.D.; Worth, A.P. Use of QSARs in international decision-making frameworks to predict ecologic effects and environmental fate of chemical substances. Environ. Health Perspect. 2003, 111, 1391-1401. [CrossRef] [PubMed]

6. Lee, Y.; Von Gunten, U. Quantitative structure-activity relationships (QSARs) for the transformation of organic micropollutants during oxidative water treatment. Water Res. 2012, 46, 6177-6195. [CrossRef] [PubMed]

7. Jaworska, J.; Nikolova-Jeliazkova, N.; Aldenberg, T. QSAR applicability domain estimation by projection of the training set in descriptor space: A review. ATLA-Altern. Lab. Anim. 2005, 33, 445-459.

8. Papp, T.; Kollar, L.; Kegl, T. Employment of quantum chemical descriptors for Hammett constants: Revision Suggested for the acetoxy substituent. Chem. Phys. Lett. 2013, 588, 51-56. [CrossRef]

9. Cocchi, M.; Menziani, M.C.; De Benedetti, P.G.; Cruciani, G. Theoretical versus empirical molecular descriptors in monosubstituted benzenes: A chemometric study. Chemom. Intell. Lab. 1992, 14, $209-224$. [CrossRef]

10. Nakano, T.; Kaminuma, T.; Sato, T.; Fukuzawa, K.; Akiyama, Y.; Uebayasi, M.; Kitaura, K. Fragment molecular orbital method: Use of approximate electrostatic potential. Chem. Phys. Lett. 2002, 351, 475-480. [CrossRef]

11. Shi, J.; Qu, R.; Feng, M.; Wang, X.; Wang, L.; Yang, S.; Wang, Z. Oxidative degradation of decabromodiphenyl ether (BDE 209) by potassium permanganate: Reaction pathways, kinetics, and mechanisms assisted by density functional theory calculations. Environ. Sci. Technol. 2015, 49, 4209-4217. [CrossRef] [PubMed]

12. Labanowski, J.K.; Andzelm, J.W. Density Functional Methods in Chemistry; Springer: New York, NY, USA, 1991.

13. Edwards, J.O.; Pearson, R.G. The factors determining nucleophilic reactivities. J. Am. Chem. Soc. 1962, 84, 16-24. [CrossRef]

14. Yang, Z.; Luo, S.; Wei, Z.; Ye, T.; Spinney, R.; Chen, D.; Xiao, R. Rate constants of hydroxyl radical oxidation of polychlorinated biphenyls in the gas phase: A single-descriptor based QSAR and DFT study. Environ. Pollut. 2016, 211, 157-164. [CrossRef] [PubMed]

15. Kohanoff, J.; Gidopoulos, N. Density functional theory: Basics, new trends and applications. In Handbook of Molecular Physics and Quantum Chemistry; John Wiley \& Sons, Ltd.: Chichester, UK, 2003; Volume 2, pp. 532-568.

16. Luo, S.; Gao, L.; Wei, Z.; Spinney, R.; Dionysiou, D.D.; Hu, W.-P.; Chai, L.; Xiao, R. Kinetic and mechanistic aspects of hydroxyl radical-mediated degradation of naproxen and reaction intermediates. Water Res. 2018, 137, 233-241. [CrossRef] [PubMed]

17. Luo, S.; Wei, Z.; Dionysiou, D.D.; Spinney, R.; Hu, W.-P.; Chai, L.; Yang, Z.; Ye, T.; Xiao, R. Mechanistic insight into reactivity of sulfate radical with aromatic contaminants through single-electron transfer pathway. Chem. Eng. J. 2017, 327, 1056-1065. [CrossRef]

18. Qu, R.; Liu, H.; Feng, M.; Yang, X.; Wang, Z. Investigation on intramolecular hydrogen bond and some thermodynamic properties of polyhydroxylated anthraquinones. J. Chem. Eng. Data 2012, 57, 2442-2455. [CrossRef]

19. Luo, S.; Wei, Z.; Spinney, R.; Zhang, Z.; Dionysiou, D.D.; Gao, L.; Chai, L.; Wang, D.; Xiao, R. UV direct photolysis of sulfamethoxazole and ibuprofen: An experimental and modelling study. J. Hazard. Mater. 2018, 343, 132-139. [CrossRef] [PubMed]

20. Xiao, R.; Ye, T.; Wei, Z.; Luo, S.; Yang, Z.; Spinney, R. Quantitative structure-activity relationship (QSAR) for the oxidation of trace organic contaminants by sulfate radical. Environ. Sci. Technol. 2015, 49, 13394-13402. [CrossRef] [PubMed]

21. Luo, S.; Wei, Z.; Spinney, R.; Yang, Z.; Chai, L.; Xiao, R. A novel model to predict gas-phase hydroxyl radical oxidation kinetics of polychlorinated compounds. Chemosphere 2017, 172, 333-340. [CrossRef] [PubMed]

22. Ye, T.; Wei, Z.; Spinney, R.; Tang, C.-J.; Luo, S.; Xiao, R.; Dionysiou, D.D. Chemical structure-based predictive model for the oxidation of trace organic contaminants by sulfate radical. Water Res. 2017, 116, 106-115. [CrossRef] [PubMed] 
23. Gross, K.C.; Seybold, P.G.; Peralta-Inga, Z.; Murray, J.S.; Politzer, P. Comparison of quantum chemical parameters and Hammett constants in correlating pKa values of substituted anilines. J. Org. Chem. 2001, 66, 6919-6925. [CrossRef] [PubMed]

24. Amat, L.; Carbó-Dorca, R.; Cooper, D.L.; Allan, N.L.; Ponec, R. Structure-property relationships and momentum space quantities: Hammett $\sigma$-Constants. Mol. Phys. 2003, 101, 3159-3162. [CrossRef]

25. Santiago, C.B.; Milo, A.; Sigman, M.S. Developing a modern approach to account for steric effects in Hammett-type correlations. J. Am. Chem. Soc. 2016, 138, 13424-13430. [CrossRef] [PubMed]

26. Hansch, C.; Leo, A.; Hoekman, D. Exploring QSAR: Fundamentals and Applications in Chemistry and Biology; American Chemical Society: Washington, DC, USA, 1995; Volume 557.

27. Sudhakaran, S.; Amy, G.L. QSAR models for oxidation of organic micropollutants in water based on ozone and hydroxyl radical rate constants and their chemical classification. Water Res. 2013, 47, 1111-1122. [CrossRef] [PubMed]

28. Russell, C.J.; Dixon, S.L.; Jurs, P.C. Computer-assisted study of the relationship between molecular structure and Henry's law constant. Anal. Chem. 1992, 64, 1350-1355. [CrossRef]

29. Kusic, H.; Rasulev, B.; Leszczynska, D.; Leszczynski, J.; Koprivanac, N. Prediction of rate constants for radical degradation of aromatic pollutants in water matrix: A QSAR study. Chemosphere 2009, 75, 1128-1134. [CrossRef] [PubMed]

30. Zetzsch, $\mathrm{C}$. Predicting the rate of $\mathrm{OH}$-addition to aromatics using $\sigma^{+}$-electrophilic substituent constants for mono-and polysubstituted benzene. In Proceedings of the 15 th Informal Conference on Photochemistry, Stanford, CA, USA, 27 June-1 July 1982.

31. Hansch, C.; Leo, A.; Taft, R. A survey of Hammett substituent constants and resonance and field parameters. Chem. Rev. 1991, 91, 165-195. [CrossRef]

32. Zeng, X.-L.; Wang, H.-J.; Wang, Y. QSPR models of n-octanol/water partition coefficients and aqueous solubility of halogenated methyl-phenyl ethers by DFT method. Chemosphere 2012, 86, 619-625. [CrossRef] [PubMed]

33. Miller, K.J. Additivity methods in molecular polarizability. J. Am. Chem. Soc. 1990, 112, 8533-8542. [CrossRef]

34. Soteras, I.; Curutchet, C.; Bidon-Chanal, A.; Dehez, F.; Angyan, J.G.; Orozco, M.; Chipot, C.; Luque, F.J. Derivation of distributed models of atomic polarizability for molecular simulations. J. Chem. Theory Comput. 2007, 3, 1901-1913. [CrossRef] [PubMed]

35. Verma, R.P.; Kurup, A.; Hansch, C. On the role of polarizability in QSAR. Bioorg. Med. Chem. 2005, 13, $237-255$. [CrossRef] [PubMed]

36. Ghanty, T.K.; Ghosh, S.K. A density functional approach to hardness, polarizability, and valency of molecules in chemical reactions. J. Phys. Chem. 1996, 100, 12295-12298. [CrossRef]

37. Kim, K.S.; Tarakeshwar, P.; Lee, J.Y. Molecular clusters of $\pi$-systems: Theoretical studies of structures, spectra, and origin of interaction energies. Chem. Rev. 2000, 100, 4145-4186. [CrossRef] [PubMed]

38. Mhin, B.J.; Lee, J.E.; Choi, W. Understanding the congener-specific toxicity in polychlorinated dibenzo-p-dioxins: Chlorination pattern and molecular quadrupole moment. J. Am. Chem. Soc. 2002, 124, 144-148. [CrossRef] [PubMed]

39. Gu, C.; Jiang, X.; Yan, D.; Bian, Y. DFT study on the relationship between the structure and water solubility of dioxin compounds. Huan jing ke xue = Huanjing kexue 2007, 28, 2651-2656. [PubMed]

40. Gu, C.; Jiang, X.; Yan, D.; Bian, Y.; Yu, G. Study on the relationship between dioxin structures and n-octanol/water partition coefficients using density functional theory (DFT). Acta Sci. Circumstantiae 2008, 2, 185-191.

41. Yan, C.L.; Chen, J.W.; Huang, L.P.; Ding, G.H.; Huang, X.Y. Linear free energy relationships on rate constants for the gas-phase reactions of hydroxyl radicals with PAHs and PCDD/Fs. Chemosphere 2005, 61, 1523-1528. [CrossRef] [PubMed]

42. Reddy, K.N.; Locke, M.A. Relationships between molecular properties and $\log P$ and soil sorption $\left(\mathrm{K}_{\mathrm{oc}}\right)$ of substituted phenylureas: QSAR models. Chemosphere 1994, 28, 1929-1941. [CrossRef]

43. Yang, G.Y.; Yu, J.; Wang, Z.Y.; Zeng, X.L.; Ju, X.H. QSPR Study on the Aqueous Solubility (- lgSw) and n-Octanol/Water Partition Coefficients (lgKow) of Polychlorinated Dibenzo- $p$-dioxins (PCDDs). QSAR Comb. Sci. 2007, 26, 352-357. [CrossRef]

44. Huang, J.; Yu, G.; Zhang, Z.-L. Application of TLSER method in predicting the aqueous solubility and n-octanol/water partition coefficient of PCBs, PCDDs and PCDFs. J. Environ. Sci. 2004, 16, 21-29. 
45. Kim, M.; Li, L.Y.; Grace, J.R. Predictability of physicochemical properties of polychlorinated dibenzo-p-dioxins (PCDDs) based on single-molecular descriptor models. Environ. Pollut. 2016, 213, 99-111. [CrossRef] [PubMed]

46. Canonica, S.; Tratnyek, P.G. Quantitative structure-activity relationships for oxidation reactions of organic chemicals in water. Environ. Toxicol. Chem. 2003, 22, 1743-1754. [CrossRef] [PubMed]

47. Dennington, R.D.; Keith, T.A.; Millam, J.M. GaussView 5.0.8; Gaussian Inc.: Wallingford, CT, USA, 2008.

48. Deppmeier, B.; Driessen, A.; Hehre, T.; Hehre, W.; Johnson, J.; Klunzinger, P.; Leonard, J.; Ohlinger, W.; Pham, I.; Pietro, W. Spartan'10. Wavefunction Inc 2011.

49. Halgren, T.A.; Nachbar, R.B. Merck molecular force field. IV. Conformational energies and geometries for MMFF94. J. Comput. Chem. 1996, 17, 587-615. [CrossRef]

50. Shao, Y.; Molnar, L.F.; Jung, Y.; Kussmann, J.; Ochsenfeld, C.; Brown, S.T.; Gilbert, A.T.; Slipchenko, L.V.; Levchenko, S.V.; O'Neill, D.P. Advances in methods and algorithms in a modern quantum chemistry program package. Phys. Chem. Chem. Phys. 2006, 8, 3172-3191. [CrossRef] [PubMed]

51. Frisc, M.; Trucks, G.; Schlegel, H.; Scuseria, G.; Robb, M.; Cheeseman, J.; Scalmani, G.; Barone, V.; Mennucci, B.; Petersson, G. Gaussian 09 (Revision C. 01); Gaussian Inc.: Wallingford, CT, USA, 2010.

52. Adamo, C.; Barone, V. Exchange functionals with improved long-range behavior and adiabatic connection methods without adjustable parameters: The mPW and mPW1PW models. J. Chem. Phys. 1998, 108, 664-675. [CrossRef]

53. Perdew, J.P.; Kieron, B.; Yue, W. Generalized gradient approximation for the exchange-correlation hole of a many-electron system. Phys. Rev. B 1996, 54, 16533. [CrossRef]

54. Easton, R.E.; Giesen, D.; Welch, A.; Cramer, C.; Truhlar, D. The MIDI! basis set for quantum mechanical calculations of molecular geometries and partial charges. Theor. Chim. Acta 1996, 93, 281-301. [CrossRef]

55. Thompson, J.D.; Winget, P.; Truhlar, D.G. MIDIX basis set for the lithium atom: Accurate geometries and atomic partial charges for lithium compounds with minimal computational cost. PhysChemComm 2001, 4, 72-77. [CrossRef]

56. Lynch, B.J.; Truhlar, D.G. Small basis sets for calculations of barrier heights, energies of reaction, electron affinities, geometries, and dipole moments. Theor. Chem. Acc. 2004, 111, 335-344. [CrossRef]

57. Tropsha, A. Best practices for QSAR model development, validation, and exploitation. Mol. Inform. 2010, 29, 476-488. [CrossRef] [PubMed]

58. SPSS Statistics for Windows, V. 17.0; SPSS Inc: Chicago, IL, USA, 2008.

Sample Availability: Samples of the compounds are not available from the authors.

(C) 2018 by the authors. Licensee MDPI, Basel, Switzerland. This article is an open access article distributed under the terms and conditions of the Creative Commons Attribution (CC BY) license (http:/ / creativecommons.org/licenses/by/4.0/). 